\title{
SORPTION OF POLYBROMINATED DIPHENYL ETHERS IN BIOSOLID MODEL SAMPLES
}

\author{
JORGE RIVAS, ${ }^{1,2}$ M. INÉS TORAL, ${ }^{2}$ PABLO RICHTER ${ }^{1,1^{*}}$ \\ ${ }^{\prime}$ Department of Inorganic and Analytical Chemistry, Faculty of Chemical and Pharmaceutical Sciences, University of Chile, P.O. Box 233, Santiago, Chile. \\ ${ }^{2}$ Department of Chemistry, Faculty of Sciences, University of Chile, P.O. Box 653, Santiago, Chile.
}

(Received: April 8, 2011 - Accepted: April 5, 2012)

\begin{abstract}
Biosolid model samples (BMSs) were developed to study the capacity of various matrixes to adsorb polybrominated diphenyl ethers (PBDEs) as a function of their composition. A commercial standard reference samples for biosolids containing a certified amount of PBDEs is currently not available for extraction evaluation. Therefore, this study will allow for the selection of an appropriate concentration of PBDEs to produce a reference material for analytes associated with the matrix.

The sorption of PBDEs increased clearly concomitantly with the amount of organic matter present in the model, revealing that organic matter rather than the inorganic fraction is mainly responsible for the analyte-matrix interaction. Hydrophobic interactions are predominant in the retention of PBDEs in the biosolid matrix because more hydrophobic congeners are generally sorbed to a higher extent than those that are less hydrophobic.

In order to know the probable PBDE sorption mechanism on the model sample of biosolid, the Gibbs free energies were calculated using the Freundlich model, giving values between -8 and $-10 \mathrm{~kJ} / \mathrm{mol}$. These results suggest that the sorption mechanism of the PBDEs is through physiosorption. Therefore, the Freundlich model should be satisfactory for describing the analyte behavior.
\end{abstract}

Keywords: PBDEs; biosolid model sample; sorption; organic matter

\section{INTRODUCTION}

Polybrominated diphenyl ethers (PBDEs) are a class of compounds extensively used as brominated flame retardants in plastics and foams, including plastic housings of electronic equipment. ${ }^{1,2,3}$ These compounds decompose at temperatures near to $300^{\circ} \mathrm{C}$ or above depending on the blends available in the plastic object ${ }^{4}$. These compounds are also highly bio-accumulative, especially in the fatty tissue of animals ${ }^{5,6,7}$. Studies in biota have demonstrated that the concentrations of PBDEs have increased with the trophic level ${ }^{8}$, suggesting biomagnification of PBDEs in aquatic ecosystems ${ }^{8,9}$. New evidence suggests that the degradation of highly brominated congeners could contribute to the accumulation of lower brominated PBDEs levels ${ }^{10,11,12}$. Studies in laboratory animals have established that PBDEs cause different toxic and harmful effects, such as liver toxicity, microsomal enzyme induction, immunological effects $^{13,14,15}$, altered neurobehavioral ${ }^{16,17}$ and reproductive effects ${ }^{18,19}$. Consequently, the use of these compounds has recently been banned as flame retardants in both the USA and European Community (EC) $)^{20}$.

Their addition as flame retardants to plastics and other polymers has caused their wide distribution in the environment because they are not strongly attached to the polymer matrix.

Wastewater has proven to be a significant source of PBDEs in the environment and these compounds have been found from micrograms to milligrams per kilogram of dry sample in biosolids around the world ${ }^{21}$. Consequently, PBDEs can reach the environment through landfills, by emission to the atmosphere during incineration of sewage sludges or when biosolids are used as soil amendments.

The concentrations of PBDEs in the environment depend on their interaction with the components of different environmental matrixes and on their physical-chemical properties, including both low solubility in water and low volatility; in particular, they tend to interact strongly with particulate matter in soils, sediments and biosolids ${ }^{22}$. Based on their log Kow values (between 5.7 and 8.3), PBDEs should be preferentially retained in the most apolar phase of solid matrixes ${ }^{23}$.

Environmental solid matrixes are complex and heterogeneous systems and their interaction with organic pollutants can occur on both the organic and inorganic phases of the matrix. Organic matter (OM) includes living organisms and complex fractions, such as the humus formed by humic and non-humic substances ${ }^{24}$; by contrast, the inorganic phase consists of primary and secondary minerals. Both phases provide sorption sites that depend on the accessibility of different sorbates.

Therefore, the interactions and mobility of organic pollutants in solid samples are complex, and there are many molecular interactions through a variety of mechanisms and transport processes.

The efficiency of an extraction analytical technique for organic analytes is usually tested using two types of reference samples: natively contaminated samples or spiked samples. There is evidence that the interactions are stronger and extraction recoveries are lower in contaminated samples than in spiked samples $^{25,26}$. However, in both cases, the interaction between the analyte and matrix is unknown, assuming that the interaction occurs mainly with low polarity organic matter ${ }^{27,28}$. Considering that organic matter content is considerably higher in biosolids than in other solid matrices, such as soils, sediments, or airborne particulate matter, the sorption of analytes may affect the efficiency of extraction of organic contaminants from the matrix to a higher extent, and thus may contribute to a decrease in the recovery. Consequently the development of BMSs can be very useful for better understanding the analytematrix interactions and for studying the efficiency of an analytical extraction technique.

The purpose of this study was to develop biosolid model samples (BMSs) with varied composition in order to study the PBDES sorption capacity of the matrix as a function of its composition. In addition, we aimed to identify a reference material for future use as a standard in analytical extraction studies. Therefore, we choose organic and inorganic materials that are representative of real biosolids to simplify the interpretation of our results.

\section{EXPERIMENTAL}

\section{Reagents}

A PBDE standard solution of $1000 \mu \mathrm{g} \mathrm{mL} \mathrm{L}^{-1}$ in methanol (Grade Lichrosolv for chromatography, Merck, Darmstadt, Germany) was prepared from the PBDE mixture Great Lakes Chemical DE-71 (2,2',4,4'-tetra-bromodiphenyl ether (BDE-47), 2,2',3,4,4'- penta- bromodiphenyl ether (BDE-85), 2,2',4,4',5-pentabromodiphenyl ether (BDE-99), 2,2',4,4',6-penta-bromodiphenyl ether (BDE-

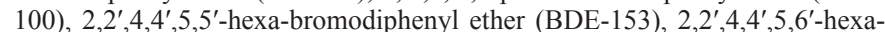
bromodiphenyl ether (BDE-154)) (Wellington Laboratories, Guelph, Ontario, Canada). This solution was then used for calibration and PBDES sorption studies.

De-ionized water (NANOpure ultrapure water system; Barnstead, Dubuque, IA, USA) was used for the preparation of all aqueous solutions.

Technical grade aluminium oxide 90 active neutral (Merck) and humic acid (HA) (Sigma-Aldrich, USA) were used as the components of the models. Humic acid was purified before use ${ }^{29}$.

In addition, $0.5 \mathrm{~mol} \mathrm{~L}^{-1}$ sodium dichromate (Merck), $100 \mathrm{mg} \mathrm{mL}^{-1}$ saccharose (Merck) and sulfuric acid (Merck) were used for the determination of organic matter in biosolid samples. Hydrogen peroxide (Merck) and hydrochloric acid (Merck) were used for oxidation of organic matter.

Finally, $0.01 \mathrm{~mol} \mathrm{~L}^{-1}$ methanol (Merck) and calcium chloride (Merck) were used for sorption studies.

A clean-up procedure was carried out using n-hexane (Grade Lichrosoly 
for chromatography, Merck), sulfuric acid, $5 \%(\mathrm{w} / \mathrm{v}) \mathrm{NaCl}$ (Merck), and $\mathrm{Na}_{2} \mathrm{SO}_{4}$ (Merck). Nitrogen ultrapure (AGA, Santiago, Chile) was used as a carrier gas in GC-ECD.

Instruments and apparatus

The $\mathrm{pH}$ measurements were performed with a pMX-3000 pH meter (WTW, Germany). The BMSs were incubated in a model C24 incubator-shaker (New Brunswick, Scientific, NJ, USA). A Reciprocal model 2020 shaker agitator (Heidolph, Germany) was used to stir the sample suspensions for the sorption studies. All suspensions were centrifuged with a model Labofurge 400 centrifuge (Heraeus Instruments, U.K.). Organic matter was determined using a $1 \mathrm{~cm}$ glass cell in a model UV-2 spectrophotometer, (ATI Unicam, U.K.). The PBDEs were determined in a Hewlett Packard model 5890 gas chromatograph with an electron capture detector.

\section{Analytical Procedures}

Preparation of BMSs

A real biosolid sample obtained from the main wastewater treatment plant, Santiago, Chile was the basic component used for the models. Its organic matter content was $44.3 \%$ and the sample had a pH of $7.01^{30}$. Using this real sample, three different biosolid models were prepared as follows:

Biosolid A: The real biosolid sample was subjected to dry digestion in a muffle furnace at $360{ }^{\circ} \mathrm{C}$ for $24 \mathrm{~h}$ to eliminate all the organic matter. Subsequently, the sample was kept for $6 \mathrm{~h}$ in a vacuum desiccator. Different portions of the digested sample were mixed with the original biosolid sample to yield five different BMSs containing different amounts of organic matter (Table 1). Each mixture was homogenized in an agate mortar for $10 \mathrm{~min}$.

Biosolid B: A second set of BMSs (biosolids B) was also prepared in which different portions of the digested sample were mixed with increasing amounts of purified humic acid. Each mixture was homogenized in an agate mortar for $10 \mathrm{~min}$. The organic matter content in each of these model samples is shown in Table 1 .

Table 1: Characterization of biosolid model samples.

\begin{tabular}{|c|c|c|c|}
\hline \multicolumn{4}{|c|}{ BIOSOLID A } \\
\hline & $\mathrm{OC}(\% \pm \mathrm{SD})$ & $\mathrm{OM}(\% \pm \mathrm{SD})$ & pH \\
\hline MODEL 1-A & BDL & BDL & $6.27 \pm 0.01$ \\
\hline MODEL 2-A & $5.2 \pm 0.9$ & $9.0 \pm 0.9$ & $6.29 \pm 0.01$ \\
\hline MODEL 3-A & $11.8 \pm 0.1$ & $20.4 \pm 0.1$ & $6.48 \pm 0.01$ \\
\hline MODEL 4-A & $16.4 \pm 0.7$ & $28.2 \pm 0.7$ & $6.67 \pm 0.01$ \\
\hline MODEL 5-A & $23.2 \pm 0.2$ & $40.0 \pm 0.2$ & $6.95 \pm 0.01$ \\
\hline \multicolumn{4}{|c|}{ BIOSOLID B } \\
\hline & $\mathrm{OC}(\% \pm \mathrm{SD})$ & $\mathrm{OM}(\% \pm \mathrm{SD})$ & pH \\
\hline MODEL 1-B & BDL & BDL & $6.27 \pm 0.01$ \\
\hline MODEL 2-B & $7.8 \pm 0.9$ & $13.5 \pm 0.7$ & $4.59 \pm 0.01$ \\
\hline MODEL 3-B & $14.7 \pm 0.1$ & $25.4 \pm 0.4$ & $4.21 \pm 0.01$ \\
\hline MODEL 4-B & $19.3 \pm 1.9$ & $33.2 \pm 1.4$ & $4.15 \pm 0.01$ \\
\hline MODEL 5-B & $24.3 \pm 0.5$ & $42.0 \pm 0.1$ & $4.02 \pm 0.01$ \\
\hline \multicolumn{4}{|c|}{ BIOSOLID C } \\
\hline & $\mathrm{OC}(\% \pm \mathrm{SD})$ & $\mathrm{OM}(\% \pm \mathrm{SD})$ & pH \\
\hline MODEL 1-C & BDL & BDL & $6.56 \pm 0.01$ \\
\hline MODEL 2-C & $5.9 \pm 0.9$ & $10.1 \pm 0.8$ & $4.68 \pm 0.01$ \\
\hline MODEL 3-C & $12.4 \pm 0.9$ & $21.3 \pm 0.3$ & $4.60 \pm 0.01$ \\
\hline MODEL 4-C & $18.7 \pm 0.6$ & $32.3 \pm 0.7$ & $4.53 \pm 0.01$ \\
\hline MODEL 5-C & $25.6 \pm 1.7$ & $44.1 \pm 1.3$ & $4.23 \pm 0.01$ \\
\hline
\end{tabular}

Biosolid C: The real biosolid sample was subjected to wet digestion of the organic matter with $30 \%(\mathrm{v} / \mathrm{v}) \mathrm{H}_{2} \mathrm{O}_{2}$ in concentrated $\mathrm{HCl}$. The inorganic residue was mixed with increasing amounts of purified humic acid to obtain five BMSs with different amounts of organic matter (Table 1). Each mixture was homogenized in an agate mortar for $10 \mathrm{~min}$.

All samples were incubated under field conditions (humidity and temperature) in order to achieve greater uniformity and similarity to a real sample.

The organic matter content of each model sample (Table 1) was determined by the modified Walkey-Black method ${ }^{30}$. BMSs

Procedure to study the effect of organic matter on PBDE sorption in
An aliquot of around $1 \mathrm{~g}$ of each BMS sample was accurately weighed in duplicate and suspended in $10.00 \mathrm{~mL}$ of methanol in separate amber glass vials. The solutions were spiked with a PBDE mixture solution at one of two concentration levels $\left(0.1\right.$ and $\left.1.0 \mathrm{mg} \mathrm{mL}^{-1}\right)$ and stirred for $15 \mathrm{~h}$. The resultant mixture was centrifuged at $2000 \mathrm{rpm}$ for $20 \mathrm{~min}$. The supernatant was evaporated almost to dryness with $\mathrm{N}_{2}$ and the solvent was changed to $5 \mathrm{~mL}$ n-hexane for clean-up treatment and gas chromatography with electron capture detector (GC-ECD) determination.

Preparation of adsorption isotherms of PBDEs on the BMSs

Aliquots (approximately $500 \mathrm{mg}$ ) of BMSs were accurately weighed in duplicate and suspended in $4 \mathrm{~mL}$ of a mixture $(1: 1, \mathrm{v}: \mathrm{v})$ of methanol and $\mathrm{CaCl}_{2}$ $0.01 \mathrm{~mol} \mathrm{~L}^{-1}$. The resultant mixtures were spiked with PBDEs mixture solution to reach final concentrations from 0.1 to $500 \mathrm{mg} \mathrm{mL}^{-1}$ and stirred at $25^{\circ} \mathrm{C}$ for $15 \mathrm{~h}$. Then, the samples were centrifuged at $2000 \mathrm{rpm}$ for $20 \mathrm{~min}$. The PBDEs present in the liquid phase were extracted with $5 \mathrm{~mL}$ of n-hexane, cleaned up, and evaluated by GC-ECD.

Clean-up procedure

The n-hexane phase containing the PDBEs was transferred to a separation funnel and then mixed with $50 \mathrm{~mL}$ of concentrated $\mathrm{H}_{2} \mathrm{SO}_{4}$. The funnel was shaken for $2 \mathrm{~min}$. After phase separation, the $\mathrm{H}_{2} \mathrm{SO}_{4}$ phase was discarded. This procedure was repeated two times. Then, three $50 \mathrm{~mL}$ aliquots of $5 \% \mathrm{NaCl}$ were sequentially added to the funnel and shaken for 2 min each time. The aqueous phase was discarded. The remaining n-hexane phase was dried by passing it through a column containing $15 \mathrm{~g}$ of anhydrous $\mathrm{Na}_{2} \mathrm{SO}_{4}$ and finally cleaned with an additional $5 \mathrm{~mL}$ of n-hexane. The n-hexane extract was then evaporated with $\mathrm{N}$ to $1 \mathrm{~mL}$ and $120 \mathrm{mg}$ of copper powder was added in order to eliminate sulfur ${ }^{31}$. At the final stage, the clean extract was evaporated to 1 $\mathrm{mL}$ under a $\mathrm{N}_{2}$ current.

Chromatographic procedure

Final determination was carried out by GC-ECD using a Zebron (Phenomenex, Torrance, CA, USA) ZB-5 fused silica capillary column (30 $\mathrm{m} \times 0.25 \mathrm{~mm}$ i.d., and $0.25 \mu \mathrm{m}$ film thickness) coated with $5 \%$ phenyl $-95 \%$ methylpolysiloxane. A $1-\mu \mathrm{L}$ sample was injected into the column using split mode (1:10). The injector temperature was $250^{\circ} \mathrm{C}$. The initial column temperature was $160{ }^{\circ} \mathrm{C}(2 \mathrm{~min})$, and increased by $10^{\circ} \mathrm{C} / \mathrm{min}$ to $260{ }^{\circ} \mathrm{C}$, and then by $1.5^{\circ} \mathrm{C} / \mathrm{min}$ to $280^{\circ} \mathrm{C}(2.0 \mathrm{~min})$. A constant flow of $1.0 \mathrm{~mL} / \mathrm{min}$ of nitrogen was used as the carrier gas. The detector was maintained at $250{ }^{\circ} \mathrm{C}$.

\section{RESULTS AND DISCUSSION}

To model the sorption behavior of organic pollutants in environmental solid matrixes, the selected materials should be representative of both the inorganic and organic fractions. Alumina and silica are essential inorganic components in the clay of soils and sediments $\mathrm{s}^{32}$ and humic acid is the representative organic component of humic substances. Because the processes of each wastewater treatment plant are different and its composition is unknown, modeling of a biosolid matrix is especially challenging.

In this study, different methods for modeling a representative biosolid containing a known content of organic matter were assessed. To control the amount of organic matter in the modeling sample, a real sample of biosolid was subjected to dry digestion in order to eliminate all the organic matter. The digested residue was then mixed with different portions of the original biosolid to yield a series of five BMSs (biosolid A) with different but known amounts of organic matter.

After dry digestion, the inorganic remaining residue could have been modified with respect to the original inorganic fraction of the biosolid. This effect could have introduced a bias in the biosolid A model because two different inorganic fractions could have been present after mixing. To minimize bias, another BMS (termed biosolid B) was prepared, in which humic acid, as a representative of organic matter, was added in different portions (five samples) to the digested biosolid.

A third alternative model (biosolid C) was prepared with wet digestion of the organic matter using $\mathrm{H}_{2} \mathrm{O}_{2}$ instead of dry digestion. After full oxidation of the organic matter, different portions of the inorganic residue were mixed with humic acid to prepare various samples.

The organic matter content and the $\mathrm{pH}$ values of the samples are shown in Table 1. A previous determination indicates that PBDEs were not detected in BMSs.

Effect of organic matter on the PBDE sorption in BMSs

When a known amount of PBDEs was added in each of the models (biosolid A, B and C), the sorption increased concomitantly with the amount of organic matter present in the model (Figure 1). The three BMSs exhibited the same behavior, verifying that the organic matter is mainly responsible for the 
PBDE-matrix interaction.

As shown in Figure 1, hydrophobic interactions mainly contribute to the PBDEs retention in the biosolid matrix; more hydrophobic congeners are sorbed to a higher extent than less hydrophobic ones (hexa-BDE> penta$\mathrm{BDE}>$ tetra-BDE) ${ }^{33}$. On the other hand, in addition to hydrophobic interactions through the aromatic rings, PBDEs can also interact via hydrogen bonds with the organic matter due to the presence of bromine and oxygen atoms. Biosolids $\mathrm{A}$ and $\mathrm{B}$ had a $\mathrm{pH}$ between 4 and 7 , thereby allowing some carboxylate and all phenol moieties to be protonated; therefore, these protons were available to form hydrogen bond, thus strengthening the sorption interaction.

Biosolid models A, B and C revealed that the main interaction between PBDEs and the matrix is via hydrophobic organic matter. If the structure of the inorganic material changed with temperature, the effect was negligible because the sorption behavior was similar for models B and C (Figure 1). Previous results ${ }^{34}$ revealed that biosolids contain variable amounts of clay, iron, manganese and aluminum oxides among other inorganic components, such as metals ( $\mathrm{Ni}, \mathrm{Mn}, \mathrm{Pb}, \mathrm{Cr}, \mathrm{Cd}, \mathrm{Zn}, \mathrm{Cu}, \mathrm{Fe}, \mathrm{Hg}$, etc), anions (chloride, hydroxides, carbonates and bicarbonates, or ammonium, potassium, phosphorus and calcium oxides $)^{35}$. The real composition of a biosolid depends to the origin of water to be treated and on the reagents used during the treatment. According the results obtained, the inorganic content does not influence the retention of the analytes (Figure 1). The amounts of these substances present in the biosolid should not be altered by the temperature used to digest organic matter in biosolid B.

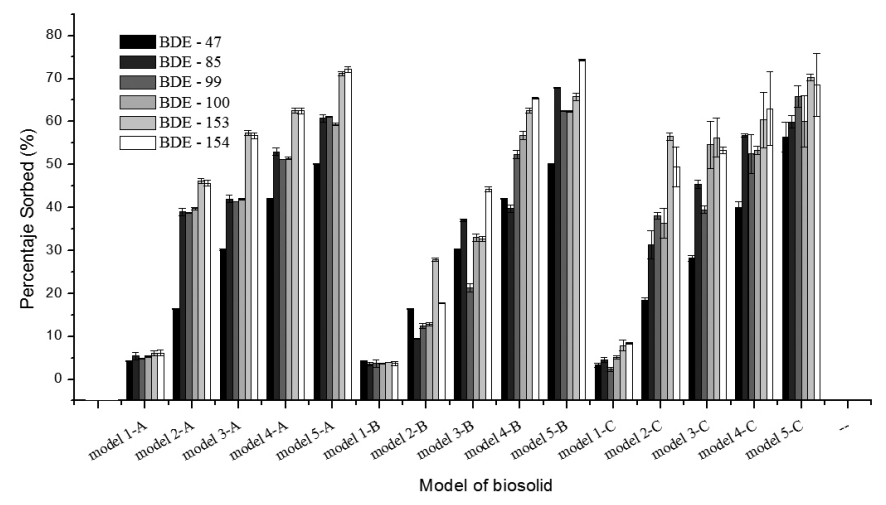

Figure 1. Sorption behavior of PBDEs in the different biosolid model samples.

Biosolid B was selected as the model for further studies because of its simplicity and homogeneity.

Adsorption isotherms

Adsorption isotherms were constructed in order to determine the maximum load of PDBEs that can be bound to the matrix without saturating the active sites. According to this result, a concentration of PDBEs will be selected in order to prepare a reference material which can be used in future studies of analytical extraction of the compounds from real biosolids.

For this study, biosolid B was the selected model as established above. Considering the typical content of organic matter in real biosolids, a model containing a $42.0 \%$ organic matter was prepared, according to the same procedure for preparation of previous model of biosolid B.

Due to the extremely low solubility of PBDEs in water $\left(6-40 \mu \mathrm{g} \mathrm{L}^{-1}\right)$, the use of pure water or aqueous solutions was not feasible for studying sorption as this effect is indistinguishable from precipitation. Consequently, a solvent mixture containing methanol and $\mathrm{CaCl}_{2} 0.01 \mathrm{~mol} \mathrm{~L}^{-1}$ in a $60: 40 \mathrm{ratio}^{36}$ was selected to keep the PDBEs dissolved after equilibrium and to maintain the ionic strength. Despite that this percentage of methanol is impractical, the constructed isotherm was useful for estimating the amount of PDBEs adsorbed by the matrix.

The equilibrium time was investigated over a range of 3 and $24 \mathrm{~h}$ under stirring. All of the studied PBDEs reached equilibrium after $6 \mathrm{~h}$, except for BDE-153, which required at least $12 \mathrm{~h}$. Therefore, a time of $15 \mathrm{~h}$ was selected to obtain the isotherms.

Previous to the adsorption studies, a blank system was analyzed to eliminate the possibility of sorption onto the beaker wall.

An adsorption isotherm is a relationship between the amount of an analyte that is adsorbed from solution and held until reaching a steady state at a constant temperature and pressure. Adsorption isotherms for PBDEs were studied in a batch system containing a fixed amount of biosolid B, and the results are shown in Figure 2.

Different models, such as Langmuir, Freundlich ${ }^{37}$, dual-mode (DMM) ${ }^{24}$, distributed reactivity $\mathrm{DRM}^{37}$ have been used to describe the sorption of organic pollutants mathematically. Table 2 shows the parameters calculated with the Langmuir and Freundlich models.

As shown in the isotherms (Figure 2), the analytes exhibited a non-linear relationship, which was also established in the values of $1 / \mathrm{n}$ (all lower than 1 ) calculated from the Freundlich model. Higher concentrations of analytes were not assayed because they are not representative of environmental matrixes. To compare the effectiveness and validity of the model, some statistical parameters were analyzed. The coefficient of determination $\left(\mathrm{r}^{2}\right)$ showed that both models are useful to explain the sorption of analytes. On the other hand, the chi-square values $\left(x^{2}\right)^{39}$ (Table 2) shown that, in general, the Freundlich model has a higher trend of correlation between the calculated and experimental data. Thus, the Freundlich model is appropriate for describe the sorption of PBDEs in the samples studied.

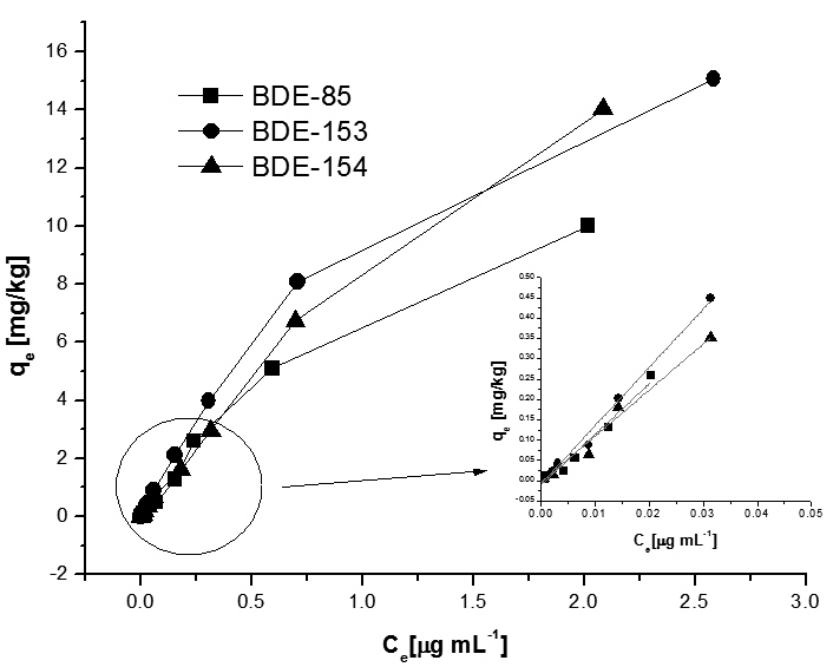

Figure 2. Adsorption isotherms for PBDEs on biosolid B.

Because organic compounds may interact with the solid matrix through different mechanisms, these models can assist with the interpretation of the sorption. In order to understand the probable sorption mechanism of the PBDEs in the model sample of biosolid, the Gibbs free energy was calculated ${ }^{40}$ by:

$$
\Delta G^{\circ}=-R T \ln K_{O C}
$$

The calculated values are shown in Table 3, indicating that the sorption process was spontaneous. The calculated $\Delta \mathrm{G}^{\mathrm{o}}$ values were between -8 and -10 $\mathrm{kJ} \mathrm{mol}^{-1}$, suggesting that the sorption mechanism of the PBDEs in the sample model of the biosolid was through physiosorption. Therefore, the Freundlich model should be satisfactory for describing the analyte behavior.

Due to the absence of commercial standard reference samples for biosolids containing a certified amount of PBDEs for extraction evaluation, this study will allow for the selection of an appropriate concentration of PBDEs to produce a reference material in which the analytes are strongly retained and not easily extracted. Therefore, an extraction technique can be assessed in regard to its capability for extracting PBDEs that interact with the matrix.

\section{ACKNOWLEDGEMENTS}

The authors thank FONDECYT (Project 1070616) for financial support and CEPEDEQ, Facultad de Ciencias Químicas y Farmacéuticas, Universidad de Chile for the use of the GC-ECD instrument. In addition, JR acknowledges CONICYT for the award of a doctoral grant to support thesis work (project AT-24080053). 


\begin{tabular}{|c|c|c|c|c|c|c|c|c|c|c|}
\hline \multirow[b]{2}{*}{ Congener } & \multicolumn{5}{|c|}{ FREUNDLICH } & \multicolumn{5}{|c|}{ LANGMUIR } \\
\hline & $\mathbf{K}_{\mathbf{F}}$ & $1 / n$ & $\mathbf{r}^{2}$ & $\mathbf{K}_{\mathrm{OC}}{ }^{*}$ & $\mathbf{x}^{2}$ & $\mathbf{Q}_{0}$ & B & $\mathbf{r}^{2}$ & $\mathbf{K}_{\mathbf{M}}^{* * *}$ & $\mathbf{x}^{2}$ \\
\hline BDE-47 & $12.9 \pm 1.9$ & $0.64 \pm 0.04$ & 0.986 & $30.7 \pm 3.2$ & 0.279 & $21.3 \pm 2.5$ & $0.061 \pm 0.005$ & 0.998 & $16.4 \pm 2.1$ & 3.953 \\
\hline BDE-99 & $13.7 \pm 0.9$ & $0.71 \pm 0.02$ & 0.998 & $32.6 \pm 4.6$ & 0.376 & $48.3 \pm 2.2$ & $0.031 \pm 0.005$ & 0.992 & $32.3 \pm 1.5$ & 0.468 \\
\hline BDE-100 & $15.0 \pm 0.7$ & $0.55 \pm 0.08$ & 0.986 & $23.8 \pm 3.1$ & 0.447 & $38.3 \pm 2.0$ & $0.043 \pm 0.006$ & 0.992 & $30.2 \pm 1.5$ & 2.73 \\
\hline
\end{tabular}

Table 3: Calculated Gibbs free energy values.

\begin{tabular}{|c|c|}
\hline Congener & $\Delta \mathbf{G}^{\circ} \mathbf{( k J ~ m o l}^{-\mathbf{1}} \mathbf{)}$ \\
\hline BDE-47 & -10.20 \\
\hline BDE-85 & -8.07 \\
\hline BDE-99 & -9.99 \\
\hline BDE-100 & -9.21 \\
\hline BDE-153 & -8.80 \\
\hline BDE-154 & -8.64 \\
\hline$\Delta \mathrm{G}^{\circ}$ calculated from the values of R: $8.314 \mathrm{~J} / \mathrm{K}$ mol and $\mathrm{T}: 298.15 \mathrm{~K}$ \\
\hline
\end{tabular}

\section{REFERENCES}

1. Chen D., Bi X., Zhao J., Chen L., Tan J., Mai B., Sheng J., Fu J., Wong M. Environ. Poll. 157, 1051 (2009)

2. Gottschall N., Topp E., Edwards M., Russell P., Payne M., Kleywegt S., Curnoe W., Lapen D.R. Sci. Total Environ. 408, 873 (2010)

3. Alaee, M., Wenning, R. J., Chemosphere 46, 579, (2002)

4. World Health Organization. Brominated diphenyl ethers. International programme on chemical safety. Environmental Health Criteria. http:// www.inchem.org/documents/ehc/ehc (1994).

5. Pan J., Yang Y-L, Xu Q., Chen D-Z, Xi D-L. Chemosphere 66, 1971, (2007)

6. Montory, M., Barra, R., Chemosphere 63, 1252, (2006)

7. Rodil, R., Carro, A. M., Lorenzo, R. A., Cela Torrijos, R.. Anal. Chem. 77, 2259, (2005)

8. Haglund, P. S., Zook, D. R., Buser, H., Hu J., Environ. Sci. Technol. 31, 3281, (1997)

9. Ackerman L., Schwindt A., Massey Simonich S., Koch D., Blett T., Schreck C., Kent M., Landers D. Environ. Sci. Technol. 42, 2334 (2008)

10. Sudaryanto A., Kajiwara N., Takahashi S., Tanabe M.S. Environ. Poll. 151130 (2008)

11. Tomy, G. T., Palace V. P., Halldorson T., Braekevelt E., Danell R., Wautier K., Evans B., Brinkworth, L., Fisk, A.T., Environ. Sci. Technol. 38, 1496, (2004)

12. Teuten, E. L., Xu, L., Reddy, C. M., Science 307, 917, (2005)

13. Tseng L., Li M., Tsai S., Lee C., Pan M., Yao W., Hsu P.Chemosphere 70, 640 (2008)

14. Kuriyama S., Wanner A., Fidalgo-Neto A., Talsness C., Koerner W., Chahoud I. Toxicology 242, 80 (2007)

15. De la Torre A., Alonso E., Concejero M.A., Sanz P., Martínez M.A. Waste Manag. 31, 1277, (2011)

16. Birnbaum, L. S., Staskal, D. F., Environ. Health Perspect. 112, 9, (2004)

17. Banasik M., Hardy M., Stedeford T. Chemosphere 77, 699, (2011)

18. Hu G., Dai J., Xu Z., Luo X., Cao H., Wang J., Mai B., Xu M. Environ. Int. 36, 309 (2010)

19. Kuriyama, S. N., Talsness, C. E., Grote, K., Chahoud, I., Environ. Health Perspect 113, 149, (2005)

20. Sánchez-Brunete, C., Miguel, E., Tadeo, J. L., Talanta 70, 1051-1056, (2006).

21. Peng, X., Tang, C., Yu, Y., Tan, J., Huang, Q., Wu, J., Chen, S., Mai B., Environ. Int. 35, 303 (2009)

22. Gouin, T., Harner, T., Environ. Int. 29, 717, (2003)

23. Braekevelt, E., Tittlemier, S., Tommy, G., Chemosphere 51, 563, (2003)

24. Sjödin, A., McGahee III, E. E., Focant, J. F., Jones, R. S., Lapeza, C. R., Zhang, Y., Patterson Jr., D. G.. Anal. Chem. 76, 4508, (2004)
25. Xiao, Q., Hu, B., Duan, J., He, M., Zu, W., J. Am. Soc. Mass Spectrom. 18, 1740, (2007)

26. Thomsen, C., Liane H., V., Becher, G., J. Chromatogr. B, 846, 252, (2007)

27. Nam, J. J., Gustafsson, O., Kurt-Karakus, P., Breivik, K., Steinnes, E., Jones, K. C., Environ. Pollut. 156, 809, (2008)

28. Liu, H., Zhang, Q., Cai, Z., Lic, A., Wang, Y., Jiang, G., Anal. Chim. Acta $\mathbf{5 5 7 , 3 1 4 , ( 2 0 0 6 )}$

29. Wang M.S., Chen S.J., Huang K.L., Lai Y.C., Chang-Chien G., Tsai J-L., Lin W.L, Chang K.C., Lee J-T, Chemosphere 80, 1220 (2010)

30. Miyazawa, M., Pavan, M.A., de Oliveira, E.L., Ionashiro, M., Silva, A.K., Braz. Arch. Biol. Technol. 43, 475, (2000)

31. U.S. Environmental Protection Agency. 1996. SW-846: Test Methods for Evaluating Solid Waste, Physical/Chemical Methods. Method 3660B: Sulfur Clean up. Revision 2. 3000 Series Methods.

32. Shin M., Duncan B., Seto P., Falletta P., Lee D-Y. Chemosphere 78, 1220 (2010)

33. Clarke B., Porter N., Symons R., Marriott P., Ades P., Stevenson G., Blackbeard J. Chemosphere 73, 980 (2008)

34. Jaynes, W. F., Zartman, R. E., Soil Sci. Soc. Am. J. 69, 1047, (2005)

35. Pio dos Reis G., Jaquiê L., Cuba F. HOLOS Environ. 9, 202 (2009)

36. Cooke, C. M., Shaw, G., Collins, C. D., Environ. Pollut. 132, 541, (2004)

37. Huang, W., Peng, P., Yu, Z., Fu, J., Appl. Geochem. 18, 955, (2003)

38. Hill, T.L. 1996. Proc. Natl. Acad. Sci. 93, 14328, (2003)

39. Ho Y-S, Wang Ch-Ch. J. Hazard. Mater. 156, 398 (2008)

40. He, Y., Xu, J., Wang, H., Ma, Z., Chen J., Environ. Res. 101, 362, (2006) 